Revista Brasileira de Farmacognosia Brazilian Journal of Pharmacognosy 21(3): 560-563, May./Jun. 2011

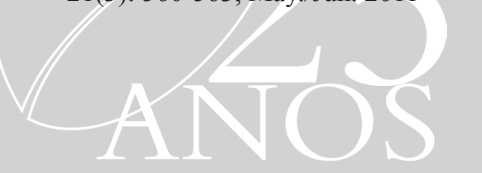

Short Communication

Received 17 Aug 2010

Accepted 7 Nov 2010

Available online 22 Apr 2011

Keywords:

oxidative stress

cholinergic stress

cottonseed

gossypol

chicken embryo

ISSN 0102-695X

doi: $10.1590 / \mathrm{S} 0102-695 \mathrm{X} 2011005000070$

\section{The developmental toxicity of cottonseed extraction on chicken embryo}

\author{
Parisa Sadighara, ${ }^{* 1}$ Jamileh Salar Amoli, ${ }^{1}$ Javad Ashrafihelan, ${ }^{2}$ \\ Tahereh Aliesfahani, ${ }^{1}$ Tahereh Farkhondeh ${ }^{1}$
}

${ }^{1}$ Department of Toxicology, Faculty of Veterinary of Tehran University, Tehran, Iran, ${ }^{2}$ Department of Pathobiology, Faculty of Veterinary of Tabriz University, Tabriz, Iran.

\begin{abstract}
Cottonseed meal is widely used as one of the protein supplement in poultry diets. Its mechanism of toxic action on chicken embryo is poorly understood. In this study, direct effects and abnormalities of cottonseed on chicken embryo were studied. Oxidative stress, cholinergic stress, mineral analysis and microscopic lesions were analyzed in chicken embryo which injected cottonseed extraction in $0.1,1$ and $10 \mathrm{mg}$ concentration (with free gossypol $0.25 \mathrm{ppm}, 2.5 \mathrm{ppm}$ and $25 \mathrm{ppm}$ respectively) at day 4 of incubation. Higher group had $100 \%$ mortality. Serum of alive chicken embryo at day 20 of incubation were measured for FRAP (ferric reducing ability of serum), total $\mathrm{SH}$ groups assay, cholinesterase assay and potassium concentration. The results expressed as mean $\pm \mathrm{SD}$ show to increase oxidative stress, cholinergic stress but significant difference $(p \leq 0.05)$ wasn't observed between groups. The significant difference was observed in potassium concentration in serum. Some evidence of hematotoxicity such as hemorrhage and higher number of puntate reticulocytes were detected. It is concluded, hematoxicity and hyperkalemia are toxicity mechanisms that could initiate in low concentrations of cottonseed in chick embryo.
\end{abstract}

\section{Introduction}

Cottonseed has a significant portion of global oilseed production (Hoffman et al., 1999). Cottonseed meal is still used in poultry diets. It contains a polyphenolic pigment which is the toxic component gossypol. Cottonseed contains 0.03 to $0.02 \%$ gossypol (Ojewola et al., 2006) and the dehulling process in increases its concentration in cottonseed meal (Nagalakshmi et al., 2007). Increasing levels of gossypol have generally been correlated with decreased hatchability of eggs. Gossypol is one of the important antinutritional factors in dietary of layers hens. The fear of gossypol toxicity is the primary concern of poultry nutritionists, limiting the incorporation of cottonseed meal (Gamboa et al., 2001). It inhibits the activity of pepsin and trypsin in gastro-intestinal tract thereby reducing the digestibility of protein (Nagalakshmi et al., 2007).

Gossypol is recognized for its toxic effect on cardiac, hepatic, pulmonary and reproductive system. It accumulated in the nerve and the results indicate that may act as a potent neurotoxin (Kanje et al., 1986). Gossypol causes oxidative stress, it interact directly with biological membranes and promote formation of highly reactive oxygen containing free radicals. Free radicals provoke oxidative injury and compromise the oxidant system of living organisms through lipid peroxidation of membranes, protein cross linkage, mitochondrial damage, and DNA damage. Potassium could account for sudden deaths without any ongoing symptoms or gross lesions seen at necroscopy (Plumlee, 2004). Plasma iron and hematocrit values were significantly reduced by gossypol at 800 and $1600 \mathrm{mg} / \mathrm{kg}$ of feed of broiler (Henry et al., 2001).

Several studies have been performed on toxicity of cottonseed in poultry. Both feed consumption and egg production were adversely affected when the diets contained 160 ppm or more free gossypol) Heywang \& Birds, 1954). Feeding of $150 \mathrm{~g}$ regular cottonseed meal kg-1diet (101.5 ppm free gossypol in diet) significantly reduced the egg production (Reid et al., 1987). The tolerance levels to gossypol in poultry is wide, it might be due to differences in age and strain of birds (Heywang \& Birds, 1955), protein quality and quantity in feed (Narain et al., 1960) and mineral contents particularly iron in diet (Bressni et al., 1964).

So far, developmental toxicity of cottonseed on chicken embryos was not examined. Therefore, the aim of the present study was to investigate direct toxic effects of cottonseed extraction on chick embryos. 


\section{Materials and Methods}

\section{Extraction}

Cottonseed ( $2 \mathrm{~g}$ ) was extracted in a Soxhlet apparatus with a mixture of methanol-acetonewater $(1: 1: 2 \mathrm{v} / \mathrm{v} / \mathrm{v})$ for $24 \mathrm{~h}$. The polar and non-polar compounds will be extracted by combination of these solvents. After that time, the solvents were removed on a rotary evaporator and transferred to vials, kept at 4 ${ }^{\circ} \mathrm{C}$. The yield of the extract was $5 \% \mathrm{w} / \mathrm{v}$. The amount of gossypol was measured with spectrophotometric method.

\section{Chemicals}

Dithionitrobenzoic acid (DTNB) (Merck, 3291), 2,4,6-tripyridyl-s-triazine(TPTZ) (Acros, 3682-35-7) and S. Acetylthiocholin Jodid (Sigma, 14H0836).

\section{Toxicity tests}

\section{Chicken embryotoxicity study}

Protocol of chicken embryotoxicity study has gained acceptance by several regulating agencies (Wolf \& Luepke, 1997). It is a sensitive, inexpensive and rapid toxicity test, providing information on embryonic lethality, teratogenicity, growth retardation, metabolism as well as systemic toxicity and imunopathological effects of chemical substance (Kemper \& Luepke, 1986).

Fertile leghorn eggs which were obtained from a breeding farm (Iran farm) on the two day. The eggs were candled on the four day. Injection eggs at day 4 of incubation are advantageous for several reasons. The viability of the egg can be positively established, as the developing vasculature is clearly visible. Another advantage is that the embryos are biased toward survival. If the embryos have been passed the first critical period of organogenesis (before day 4 of development), their chances of surviving to hatch are improved, which increases the number of samples for posthatch studies (DeWitt et al., 2005).

Infertile and damaged eggs were discarded. Following sterilization with ethanol, the eggs were drilled. Infertile and damaged eggs were discarded. The eggs were distributed into two groups of 30 (test substance) and 10 (control). Extraction of cottonseed was injected in $0.1,1$ and $10 \mathrm{mg}$ concentration (with free gossypol $0.25,2.5$ and $25 \mathrm{ppm}$ respectively) into the egg yolk. The eggs were closed with paraffin and placed in an incubator at $37.5 \pm 0.1{ }^{\circ} \mathrm{C}$ and $50-60 \%$ relative humidity. The eggs were candled the day after injection and thereafter every $48 \mathrm{~h}$ for checking dead embryos. The dead embryos were fixed in $10 \%$ neutral formalin for microscopic examination. The experiment was terminated on day 20 of incubation. Embryos were removed; decapitated, observed malformation and gross lesions. Blood of live embryos was collected for biochemical analysis also blood smears were prepared.

\section{The tests for oxidative stress}

FRAP (ferric reducing ability of serum) assay

Antioxidant capacity of serum was determined by measuring the ability of serum to reduce $\mathrm{Fe}^{3+}$ to $\mathrm{Fe}^{2+}$. The complex between $\mathrm{Fe}^{2+}$ and TPTZ gives a blue color with absorbance at $593 \mathrm{~nm}$ (Hu \& Dillard, 1994).

\section{Total SH groups assay}

Total SH groups of serum was measured spectrophotometrically at $412 \mathrm{~nm}$ using DTNB as the reagent (Iris et al., 1994).

\section{Cholinergic stress}

\section{Cholinesterase assay}

The measurement of cholinesterase is well established. Potassium phosphate buffer and DTNB were added to serum samples. Then acetylthiocholine iodide was added and the absorbance at $412 \mathrm{~nm}$ was read by spectrophotometer (Ellman et al., 1961).

\section{Gross lesion}

Embryos on the day 20, also dead embryos which were dying during study, were observed for abnormalities.

\section{Microscopic lesion}

The tissues of dead embryos were embedded in paraffin, sectioned at $6 \mu$ and stained with H\&E for histopathology.

\section{Mineral studies}

Potassium in serum samples were determined by atomic absorption spectrophotometry after wet ashing with a hydrochloric acid.

\section{Statistical analysis}

The data were tested by analysis of T-Test in SPSS software. The evaluation was made by comparing 
groups. The difference more than 95\% $(p \leq 0.05)$ was considered significant.

\section{Results}

Results of cholinergic stress, oxidative stress assay and potassium concentration are presented in Table (1). The results expressed as mean $\pm \mathrm{SD}$ show to increase oxidative stress, cholinergic stress but significant difference $(p \leq 0.05)$ wasn't observed between groups.

Table 1. The effect of cottonseed extraction on chicken embryos.

\begin{tabular}{lcccc}
\hline & Control & $0.1 \mathrm{mg} / \mathrm{egg}$ & $1 \mathrm{mg} / \mathrm{egg}$ & $10 \mathrm{mg} / \mathrm{egg}$ \\
\hline $\mathrm{N}$ & 10 & 10 & 10 & 10 \\
Survival (\%) & 90 & 70 & 70 & 0 \\
\hline \multicolumn{5}{c}{ Serum examination } \\
\hline $\begin{array}{l}\text { Total SH } \\
(\mathrm{mM})\end{array}$ & $0.36 \pm 0.2$ & $*$ & $0.33 \pm 0.08$ & - \\
$\begin{array}{l}\text { FRAP (mM) } \\
\text { ChE activity } \\
(\mu \mathrm{moL} / \mathrm{mL} /\end{array}$ & $0.352 \pm 0.08$ & $0.267 \pm 0.12$ & $0.244 \pm 0.02$ & - \\
min) & & $3.67 \pm 0.5$ & $3.04 \pm 2.3$ & - \\
$\begin{array}{l}\text { Potassium } \\
(\mathrm{ppm})\end{array}$ & $787.9 \pm 162$ & $992.8 \pm 188$ & $2399.9 \pm 88$ & - \\
\hline
\end{tabular}

*Serum of these groups was little for measuring of total SH.

The significant difference was observed in potassium concentration in serum between groups. Macroscopic lesion (except hemorrhage) and developmental abnormalities was not observed on embryos that were opened on day 20. Administration of the highest dose of the extraction resulted in $100 \%$ mortality of the embryos. In dead embryos, many hemorrhages, petechial and ecchymotic in size, with accumulation of thin gray scale-crust were observed in skin. These lesions were developed over the whole body but were most severe on the neck, back, thigh and forelegs. Numerous petechial hemorrhages in epicardial fat were present. Microscopically, often subcutaneous tissue was congested, with mild superficial perivascular lymphocytes accumulation and there was severe edema mainly in the form of numerous plaque-like subcutaneous swelling, several millimeters in diameter suggestive of urticaria. The cutaneous hemorrhages frequently bleed in these spaces suggestive of subcutaneous hemal cysts. Severe congestion and evidences of single cell necrosis were observed in the liver. Extramedullary hematopoiesis centers were severely decreased. Central nervous system was congested and edematous with focal leukoencephalomalacia and hemorrhages. Severe congestion of retina and periorbital tissue with focal infiltration of lymphocytes was present. The heart, kidneys, skeletal muscles, tracheal mucosa and lungs were congested and edematous.

In blood smears, the $1 \mathrm{mg}$ groups had a higher number of puntate reticulocytes than other groups on blood smears.

The most deaths occurred during the first $24 \mathrm{~h}$ after administration. In the other treatment groups $(0.1$, $1 \mathrm{mg}$ concentration) rate mortality was approximately $30 \%$ that majority were early dead (before day 12 of development).

\section{Discussion and conclusions}

Developmental duration can be affected by many factors such as antinutrient in dietary of layer hens. Gossypol in cottonseed is one of the most important undesirable substance and major concern. Laying hens fed diets containing gossypol can cause high mortality in embryos. It also causes micromelia and gastroschisis in embryos. There is enough evidence about embryotoxic and teratogenic activity of gossypol in chick embryos.

In this paper, direct toxicity of cottonseed on chick embryo was investigated. Chick embryos has used as a model system for developmental toxicity because. In this study, we focused on oxidative stress; one of the mechanisms is involved in developmental toxicity of gossypol.

Generation of free radicals, alteration of ion transport disruption of cell-to-cell communication, and induction of apoptosis have been known as toxicity mechanism of gossypol. Oxidative stress damages to biological membranes and promotes formation of highly reactive oxygen containing free radicals. Free radical damages embryonic macromolecules and cause teratogenesis. One of mechanism of teratogens is oxidative stress. Oxidative stress wasn't observed in our study. Therefore embryo protective pathways against oxidative stress can decrease the risk of free radical in these concentrations. Our evidence confirmed these results because special abnormalities and malformed embryo weren't observed.

With attention to toxic effect of gossypol upon CNS, ChE activity was measured. The cholinergic system is highly vulnerable to oxidative stress. Pervious study has showed that gossypol to be an uncompetitive inhibitor of this enzyme but in this research embryo defective mechanism against oxidative stress inhibited this effect of gossypol.

Hemorrhage and puntate reticulocytes were observed. Reticulocytosis indicates increased bone marrow erythropoiesis and release of erythrocytes before they are fully mature and it is a response to anemia (Nagalakshmi et al., 2007). Lowering of hemoglobin and total erythrocytic count are classical signs of gossypol therefore it could be caused hematotoxicity in 
these ranges.

Hyperkalemia was also observed (Table 1). According to previous studies cardiac failture similar to hyperkalemia heart failure was recorded.

Embryo mortality at earlier stages of development, approximately before day 12 of development, is classified early dead (Blankenship et al., 2003). We faced early dead therefore cottonseed can cause mortality at earlier stages of chicken embryo development. With attention to related reporter in this field, all animal species in early embryonic stage are susceptible to gossypol.

Collectively, our experience shows hyperkalemia and hematotoxicity might initiate in low concentrations of cottonseed in chick embryo.

\section{References}

Blankenship AL, Hilscherova K, Nia M, Coady KK, Villalobos SA, Kannan K, Powell DC, Bursian SJ, Giesy JP 2003. Mechanism of TCDD induced abnormalities and embryo lethality in white leghorn chickens. Comp Biochem Physiol 136: 47-62.

Bressani R, Elias LG, BrahamA JE 1964. All-vegetable protein mixture for human feeding. 15. Studies in dogs on the absorption of gossypol from cottonseed flour containing vegetable protein mixtures. $J$ Nutr 83: 209-217.

DeWitt JC, Meyer EB, Henshel DS 2005. Environmental toxicity studies using chickens as surrogates for wildlife: effects of injection day. Arch Environ Contam Toxicol 48: 270-277.

Ellman G, Counrtney K, Andres VJR 1961. A new and rapid colorimetric determination of acetylcholinesterase activity. Biochem Pharmacol 7: 88-95.

Gamboa DA, Calhoun MC, Kunlmann SW, Haq AU, Bailey CA 2001. Use of expander cottonseed meal in broiler diets formulated on a digestible amino acid basis. Poult Sci 80: 789-794.

Henry MH, Pesti GM, Brown TP 2001. Pathology and Histopathology of Gossypol Toxicity in Broiler Chicks. Avian Dis 45: 598-604.

Heywang BW, Birds HR 1954. Egg production, diet consumption and live weight in relation to the free gossypol content of the diet. Poult Sci 33: 851-854.
Heywang BW, Birds HR 1955. Relation between the weight of chicks and levels of dietary free gossypol supplied by different cottonseed products. Poult Sci 34: 12391247.

Hoffman L, Dohlman E, Ash M 1999. Upcoming world trade organization negotiations: issues for the U.S. oil seed sector. http://www.usda.gov.htm.

Hu ML, Dillard CJ 1994. Ferric reducing antioxidant assay. Meth Enzymol 292: 15-27.

Iris F, Benzi F, Strain S 1994. Plasma SH and GSH measurment. Meth Enzymol 233: 385-387.

Kanje M, Ekstrom P, Deinum J, Wallin M 1986. The effects of gossypol on fast axonal on fast axonal transport and microtubule assembly. Biochim Biophys Acta 25: 473-42.

Kemper FH, Luepke NP 1986. Toxicity testing by hen's egg test (HET). Food Chem Toxicol 24: 647-648.

Nagalakshmi D, Rama Rao S, Panda A, Sastry V 2007. Cottonseed meal in poultry diets. J Poult Sci 44: 119134.

Narain R, Lyman CM, Deyoe CW, Couch JR 1960. Effects of protein level of the diet on free gossypol tolerance in chicks. Poult Sci 39: 1556-1559.

Ojewola GS, Ukachukwu SN, Okulonye EL 2006. Cottonseed meal as substitute for soyabean meal in broiler ration. $J$ Poult Sci 5: 360-364.

Plumlee KH 2004. Clinical Veterinary Toxicology. Saint Louis: Mosby INC.

Reid BL, Galaviz-Moreno S, Maiorino PM 1987. Evaluation of isopropanol-extracted cottonseed meal for laying hens. Poult Sci 66: 82-89.

Wolf T, Luepke NP 1997. Formation of micronuclei in incubated hen's eggs as a measure of genotoxicity. Mutat Res 394: 163-175.

\section{*Correspondence}

\section{Parisa Sadighara}

Department of Toxicology, Faculty of Veterinary of Tehran University

Azadi Street, 14155-6453, Tehran, Iran.

sadighara@vetmed.ut.ac.ir

Tel. +98 2161117027

Fax: +98 2166933222 